\title{
Wholegrain foods made from a novel high-amylose barley variety (Himalaya 292) improve indices of bowel health in human subjects
}

\author{
Anthony R. Bird ${ }^{1 *}$, Michelle S. Vuaran ${ }^{1}$, Roger A. King ${ }^{1}$, Manny Noakes ${ }^{1}$, Jennifer Keogh ${ }^{1}$, \\ Matthew K. Morell ${ }^{2}$ and David L. Topping ${ }^{1}$ \\ ${ }^{1}$ CSIRO Human Nutrition, Kintore Avenue, Adelaide 5000, Australia \\ ${ }^{2}$ CSIRO Plant Industry, GPO Box 1600, Canberra, ACT 2601, Australia
}

(Received 7 June 2007 - Revised 21 August 2007 - Accepted 22 August 2007 - First published online 8 October 2007)

Himalaya 292 (Hordeum vulgare var. Himalaya 292) is a novel hull-less barley variety lacking activity of a key enzyme of starch synthesis giving a grain containing less total starch, more amylose and higher total dietary fibre. Animal trials have shown that Himalaya 292 contains more resistant starch and has greater positive impact on biomarkers of large-bowel health than comparable wholegrain cereal products. The present study compared the effects of foods made from wholegrain Himalaya 292 with those made from wholegrain wheat on faecal biomarkers of bowel health in human subjects. Seventeen male and female volunteers aged 31-66 years consumed similar quantities of Himalaya 292, wholewheat or refined cereal foods daily for 4 weeks in a randomised cross-over design. Total dietary fibre intakes from weighed food records were 45, 32 and $21 \mathrm{~g} / \mathrm{d}$ for the Himalaya 292, whole-wheat and refined cereal periods, respectively. Compared with the refined cereal foods, consumption of Himalaya 292 foods resulted in $33 \%$ higher faecal weight, a lowering of faecal pH from 7.24 to 6.98, a $42 \%$ higher faecal concentration and a $91 \%$ higher excretion of butyrate, a $57 \%$ higher faecal total SCFA excretion and a $33 \%$ lower faecal $p$-cresol concentration. $\mathrm{pH}$ and butyrate concentration and excretion were also significantly different compared with wholemeal wheat. It is concluded that consumption of a diet that included foods made from Himalaya 292 supplied more fibre and improved indices of bowel health compared with refined cereal foods and, for some indices, similar wholemeal wheat foods at equivalent levels of intake.

Barley: Resistant starch: Wheat: Whole grains

The 1995 National Nutrition Survey in Australia found that only $34 \%$ of men and $21 \%$ of women met the recommended number of daily servings of whole grains ${ }^{1}$. This is despite the advice in national dietary guidelines for adults to increase the consumption of wholegrain cereals ${ }^{2,3}$. Population studies have linked the consumption of wholegrain cereal foods with lowered risk of certain cancers (especially of the colon and rectum), $\mathrm{CHD}$ and diabetes ${ }^{4-6}$. Increased consumption of wholegrain cereals correlates negatively with obesity ${ }^{7}$, itself an important risk factor for greater morbidity and mortality.

Whole grains contain complex carbohydrates - starch and NSP - which can improve health status through a number of mechanisms. NSP resist human small-intestinal digestive enzymes completely, contributing to their faecal bulking and laxative properties ${ }^{8}$. NSP are the principal components of dietary fibre and fibre-rich foods and are well established in the promotion of normal colonic function and prevention of functional disease $^{8,9}$. A large multi-centre population study (European Prospective Investigation into Cancer and Nutrition; EPIC) has also shown that dietary fibre (measured using countryspecific methods) is protective against colorectal cancer ${ }^{10}$.

Plant polysaccharides improve large-bowel health by mechanisms other than increasing stool mass. A fraction of NSP is fermented by the large-bowel microflora, providing the bacteria with energy for growth and maintenance and yielding SCFA ${ }^{11}$. One of the major acids, butyrate, is thought to be especially important for bowel health and an increasing body of experimental evidence suggests that it acts to promote a normal phenotype in colonocytes and, hence, lower the risk of colorectal cancer $^{12,13}$. Early studies (for example, those of Burkitt ${ }^{14}$ ) on low-risk African populations who consumed diets high in unrefined foods led to the conclusion that greater dietary fibre was responsible for the protection. However, it is becoming apparent that at least for some low-risk groups (including the Africans), their intakes of fibre are not especially high ${ }^{13,15}$. Studies in southern Africa have shown that one of those low-risk groups consumes diets high in starch, including resistant starch (RS) ${ }^{15}$. RS is that fraction of ingested starch which enters the large bowel where it is fermented by the microflora, leading to greater SCFA production ${ }^{12,13}$. RS fermentation seems to favour butyrate production ${ }^{16}$. This may explain the apparent protection against colorectal cancer conferred by dietary $\operatorname{starch}^{17}$. Studies with ileostomists and normal volunteers have confirmed high levels of colonic and faecal SCFA (including butyrate) in Africans consuming traditional foods putatively high in RS but low in fibre ${ }^{15}$.

Abbreviations: CSIRO, Commonwealth Scientific and Industrial Research Organisation; DM, dry matter; NSP, Non-starch polysaccharides; RS, resistant starch; SCFA, short chain fatty acids; TDF, total dietary fibre.

* Corresponding author: Dr A. R. Bird, fax +61 88303 8899, email tony.bird@csiro.au 
Support for beneficial effects of butyrate on colonocyte integrity has come from a range of studies. A human trial has shown that higher faecal butyrate was associated with lower colonocyte proliferation ${ }^{18}$. Butyrate supplied directly to the colon has been shown to oppose azoxymethane-induced large-bowel cancer in rats ${ }^{19}$. More recently, animal studies have shown diet-induced colonocyte genetic damage was inversely related to large-bowel butyrate content ${ }^{20}$. The optimal effects of complex carbohydrates on large-bowel function appear to be obtained through combining RS and $\mathrm{NSP}^{21}$. NSP and RS consumption is relatively low in many countries ${ }^{22,23}$. RS occurs for a variety of reasons including cooking, the presence of dietary fibre and the relative proportions of amylose and amylopectin in $\operatorname{starch}^{24}$. Amylose gelatinises slowly on cooking and retrogrades more quickly on cooling compared with amylopectin ${ }^{25}$. The amylose content of most cereal food starches is $\leq 30 \%$ and raising its contribution through selective cereal breeding has been used to supply RS via processed foods ${ }^{24}$. Recently, a novel variety of a waxy, hull-less barley (Hordeum vulgare var. Himalaya 292; Himalaya 292) with a single genetic change in the pathways of starch synthesis has been identified and grown in quantity ${ }^{26}$. This change is located in the gene encoding starch synthase IIa (SSIIa; EC 2.4.1.21) and results in a shrunken grain containing less total starch but a greater proportion of amylose and a much higher content of total and soluble NSP (including $\beta$ glucan). Animal feeding studies have shown that this new variety contains more RS than other wholegrain cereals and has the potential to improve indices of large-bowel health ${ }^{27,28}$. Himalaya 292 has been used to make human foods and the aim of the present study was to determine, in free-living human volunteers, whether foods made from this barley have greater capacity to improve those indices than current wholegrain foods at equivalent levels of intake.

\section{Subjects and methods}

\section{Subjects}

Prospective volunteers were sought by local advertisement and screened using a dietary and health questionnaire and blood tests. Exclusion criteria were a history of diabetes, gastrointestinal, renal, hepatic and cardiovascular disease, an intolerance to cereal-based foods, fasting plasma glucose concentrations $>6.1 \mathrm{mmol} / \mathrm{l}$ and medications or supplements likely to affect experimental endpoints.

Twenty-four subjects, eleven men and thirteen women, were enrolled in the study. Three of these withdrew before the study commenced while three dropped out during the first intervention phase, which was the Himalaya 292 phase for these three volunteers, due to either personal reasons, an inability to eat the required amount, or abdominal discomfort attributed to the bulkiness of the study foods. Baseline characteristics of the ten men and eight women who completed the study were: age 55.9 (SE 2.0; range 31-66) years; weight 79.5 (SE 3.6; range 57-109) kg; BMI 27.2 (SE 1.2; range $21-38) \mathrm{kg} / \mathrm{m}^{2}$.

The study was explained fully to the subjects, both verbally and in writing, and each gave their written, informed consent before participating. The study was approved by the Human
Ethics Committee of the Commonwealth Scientific and Industrial Research Organisation (CSIRO).

\section{Study foods}

Himalaya 292 grain was developed and supplied by CSIRO Plant Industry (Black Mountain, ACT, Australia). The grain was first heat stabilised with steam under pressure by Food Science Australia (North Ryde, NSW, Australia). The jacket temperature in the cooker was $100-120^{\circ} \mathrm{C}$, with steam delivered at $110 \mathrm{kPa}$ for $12 \mathrm{~min}$, followed by vacuum at $-80 \mathrm{kPa}$ for $20 \mathrm{~min}$. Study foods were breakfast cereal, sweet muffins, bread and savoury cracker biscuits which were formulated and manufactured under contract by the Bread Research Institute (BRI; North Ryde, NSW, Australia). The stabilised barley grain was milled by the BRI to specifications appropriate for each of the foods. White (refined) and wholemeal wheat flours of specifications appropriate for each food application were obtained by the BRI from commercial sources.

Recipes for bread, sweet muffins and savoury cracker biscuits were developed to enable the maximum possible inclusion of Himalaya 292 consistent with a product that would be acceptable to study participants. The levels of inclusion of Himalaya 292 (as wholemeal flour) in the final products were: bread, $20 \%$; crackers, $37 \%$; muffins, $21 \%$. For corresponding wholemeal wheat products, wholemeal wheat flour replaced Himalaya 292 flour and for refined cereal products white wheat flour replaced Himalaya 292 flour. All other ingredients were identical for the Himalaya 292, wholemeal wheat and refined wheat products. Breakfast cereal flakes comprised either $100 \%$ wholegrain Himalaya 292 or $100 \%$ wholegrain wheat. Because it was not possible to make a refined wheat-flake product, a commercial puffed rice breakfast cereal (Coles Farmland, Gepps Cross, SA, Australia) was used in the refined cereal diet. The nutrient composition of Himalaya 292 has been published previously ${ }^{27,29}$. The composition of the study foods is presented in Table 1.

The foods were produced in three batches at approximately monthly intervals and shipped to CSIRO Adelaide (Australia). Bread and muffins were transported frozen and stored at $-20^{\circ} \mathrm{C}$ at CSIRO until required. Flakes and crackers were shipped and stored at room temperature. Puffed rice breakfast cereal was purchased at a local supermarket and stored at room temperature.

\section{Study design and diets}

Subjects were allocated randomly to one of three dietary treatments according to a cross-over study design with each intervention phase lasting 4 weeks. There was no washout period between phases. The habitual diet of each subject was modified to incorporate Himalaya 292, wholemeal wheat or refined cereal-based treatment foods. On each day of the intervention periods, volunteers were asked to consume a combination of bread, breakfast cereal, muffins and crackers that would supply in total $103 \mathrm{~g}$ of the test cereal. The aim was for each volunteer to consume $60 \mathrm{~g}$ cereal flakes (or puffed rice for the refined cereal diet), two slices of bread, one muffin and six savoury crackers each day. Volunteers were not told the identity of the test cereal in the foods provided to them. Subjects were seen by a research dietitian at the beginning 
Table 1. Nutrient composition of the cereal-based treatment foods consumed by volunteers*

(Mean values of duplicate determinations)

\begin{tabular}{|c|c|c|c|c|c|c|c|c|}
\hline \multirow[b]{2}{*}{ Cereal treatment and food type } & \multirow[b]{2}{*}{ Moisture } & \multirow[b]{2}{*}{ Starch } & \multirow[b]{2}{*}{ Protein } & \multirow[b]{2}{*}{ Fat } & \multirow[b]{2}{*}{ Sugars } & \multirow[b]{2}{*}{ Total dietary fibre $†$} & \multicolumn{2}{|c|}{ Neutral NSP } \\
\hline & & & & & & & Soluble & Insoluble \\
\hline \multicolumn{9}{|l|}{ Himalaya 292 (g/100 g product $\ddagger)$} \\
\hline Breakfast cereal & 6.5 & 29.7 & $15 \cdot 0$ & $7 \cdot 2$ & $7 \cdot 8$ & $26 \cdot 5$ & 8.4 & 11.5 \\
\hline Bread & $42 \cdot 5$ & $39 \cdot 6$ & $10 \cdot 4$ & 5.1 & 3.9 & 8.4 & $2 \cdot 2$ & 3.2 \\
\hline Muffin & $32 \cdot 8$ & $13 \cdot 0$ & $5 \cdot 8$ & 19.5 & $17 \cdot 0$ & 5.9 & 1.8 & $2 \cdot 6$ \\
\hline Cracker & $8 \cdot 2$ & 39.6 & $13 \cdot 2$ & $9 \cdot 2$ & $11 \cdot 0$ & $14 \cdot 3$ & 4.4 & $6 \cdot 2$ \\
\hline \multicolumn{9}{|l|}{ Wholemeal wheat } \\
\hline Breakfast cereal & $9 \cdot 6$ & 63.4 & $10 \cdot 8$ & 3.0 & 1.7 & $12 \cdot 4$ & 1.8 & 7.7 \\
\hline Bread & $40 \cdot 0$ & $50 \cdot 1$ & $11 \cdot 2$ & $2 \cdot 7$ & 3.5 & 4.6 & 0.6 & $2 \cdot 6$ \\
\hline Muffin & $25 \cdot 7$ & $20 \cdot 7$ & $5 \cdot 8$ & $21 \cdot 8$ & $18 \cdot 8$ & 3.6 & 0.4 & 1.9 \\
\hline Cracker & $7 \cdot 2$ & 57.5 & 12.9 & $5 \cdot 8$ & $7 \cdot 0$ & 7.9 & 1.6 & 4.9 \\
\hline \multicolumn{9}{|l|}{ Refined cereal } \\
\hline Breakfast cereal & 3.4 & 79.9 & $6 \cdot 1$ & 0.9 & $11 \cdot 6$ & 1.9 & 0.2 & 0.6 \\
\hline Bread & 38.9 & $52 \cdot 9$ & $10 \cdot 5$ & 3.4 & 3.8 & $4 \cdot 0$ & 0.9 & 1.7 \\
\hline Muffin & $26 \cdot 3$ & 24.4 & 4.9 & 18.5 & $23 \cdot 2$ & 1.5 & 0.4 & 0.8 \\
\hline Cracker & 8.8 & 61.6 & $12 \cdot 9$ & 5.8 & 7.5 & 3.5 & 1.1 & 1.9 \\
\hline
\end{tabular}

* Volunteers consumed the following servings of each food on a daily basis for each intervention phase: $60 \mathrm{~g}$ breakfast cereal, two slices of bread (76 g), six crackers $(19-24 \mathrm{~g})$ and one muffin $(85-95 \mathrm{~g})$.

tDetermined by the Prosky procedure.

$\ddagger$ On an 'as-is' basis.

of each intervention for advice on a low-fibre intake background diet $(<15 \mathrm{~g} / \mathrm{d})$ and to assist in the accommodation of the test foods in their diet without changing total energy intake. They were also seen after 2 weeks to ensure compliance with the test foods and background diet. In a few cases it was necessary to reduce the designated serving size of a test food in order to satisfy individual preference but in most instances the loss in intake could be offset by a proportional increase in consumption of another test food from the same treatment. All other foods eaten during the study were provided by the volunteer and they were instructed to avoid consuming foods, or supplements, that were high in fibre or contained probiotics (for example, yoghurts), and to record study food consumption on a checklist. Dietary intake data are summarised in Table 2.

\section{Study protocol and sample collections}

The volunteers visited the Clinical Research Unit during week 0 and at the end of weeks $2,4,6,8,10$ and 12. To monitor intake of individual foods, volunteers were instructed to maintain $3 \mathrm{~d}$ weighed food records in the period before the study commenced (baseline, week 0) and then at the end of each 4-week intervention period. At each clinic visit, volunteers returned any uneaten test foods, which were weighed in order to assess compliance, and collected their allocation of

Table 2. Estimated daily energy and nutrient intakes for the three dietary interventions (Mean values with their standard errors for seventeen observations)

\begin{tabular}{|c|c|c|c|c|c|c|}
\hline & \multicolumn{2}{|c|}{ Refined cereal } & \multicolumn{2}{|c|}{ Wholemeal wheat } & \multicolumn{2}{|c|}{ Himalaya 292} \\
\hline & Mean & SE & Mean & SE & Mean & SE \\
\hline Energy (kJ) & 8781 & 527 & 9289 & 535 & 8834 & 539 \\
\hline Protein $(\mathrm{g})$ & $97 \cdot 7$ & 6.4 & $106 \cdot 1$ & $6 \cdot 3$ & $104 \cdot 4$ & $6 \cdot 8$ \\
\hline Protein (\% energy) & $18 \cdot 2$ & 0.9 & $18 \cdot 4$ & 0.6 & $19 \cdot 0$ & 0.6 \\
\hline Fat $(\mathrm{g})$ & $65 \cdot 2$ & $6 \cdot 2$ & $76 \cdot 2$ & $7 \cdot 6$ & $62 \cdot 7$ & $6 \cdot 3$ \\
\hline Fat (\% energy) & $27 \cdot 2$ & $1 \cdot 7$ & $29 \cdot 8$ & $2 \cdot .0$ & $25 \cdot 7$ & $1 \cdot 6$ \\
\hline Carbohydrate (g) & $271 \cdot 0$ & $17 \cdot 7$ & $270 \cdot 8$ & $15 \cdot 4$ & $275 \cdot 1$ & $17 \cdot 0$ \\
\hline Carbohydrate (\% energy) & 52.5 & $2 \cdot 2$ & $50 \cdot 0$ & $1 \cdot 8$ & 53.5 & $1 \cdot 7$ \\
\hline Alcohol (g) & $6 \cdot 0$ & $2 \cdot 2$ & 4.5 & $2 \cdot 2$ & 5.5 & $2 \cdot 1$ \\
\hline Alcohol (\% energy) & $1 \cdot 8$ & 0.7 & $1 \cdot 3$ & 0.6 & $1 \cdot 7$ & 0.6 \\
\hline Fibre $(g)^{*}$ & 21.4 & 1.8 & 32.4 & $2 \cdot 0$ & $44 \cdot 6$ & $2 \cdot 5$ \\
\hline Sugar (g) & $94 \cdot 1$ & $8 \cdot 6$ & 93.3 & $11 \cdot 3$ & $101 \cdot 9$ & $12 \cdot 7$ \\
\hline Starch (g) & $176 \cdot 4$ & $14 \cdot 1$ & $176 \cdot 8$ & 7.5 & $172 \cdot 8$ & $9 \cdot 8$ \\
\hline
\end{tabular}

*Estimated total dietary fibre intake was significantly higher in the wholemeal wheat group compared with the refined cereal group ( $F$ ratio 7.931, $P=0.001$; repeated-measures ANOVA) $(P=0.013$; Bonferroni post hoc test), and in the Himalaya 292 group compared with the refined wheat group $(P=0.001$; Bonferroni post hoc test) and the wholemeal wheat group ( $P=0.001$; Bonferroni post hoc test). There were no statistically significant differences between the three groups using repeated-measures ANOVA for energy, protein, fat, carbohydrate, sugar or starch.

† Results were based on self-reported dietary intakes. 
test foods for the next 2 weeks. The volunteers were also weighed and the background diet adjusted accordingly, in consultation with a study dietitian, if significant weight change had occurred. At all visits a study dietitian counselled volunteers to motivate them and encourage compliance.

Complete $48 \mathrm{~h}$ faecal collections were made by all participants at the end of each intervention period (weeks 4,8 and 12). A plastic bag was placed over the toilet bowl to collect each stool. Air was expelled from the plastic bag, which was then sealed, labelled and frozen $\left(-20^{\circ} \mathrm{C}\right)$ and taken to the Clinical Research Unit to await laboratory analyses. Separate bags were used for each bowel motion. Defecation frequency was calculated according to the number of bags used per collection period. A spot urine sample was obtained from each volunteer during their clinic visit and immediately frozen $\left(-80^{\circ} \mathrm{C}\right)$ to await analysis. Samples of each cereal test food were obtained during the second intervention period and analysed for macronutrients and total dietary fibre (TDF).

\section{Assessment of nutrient intake and compliance}

Volunteers were provided information on recording the amount and type of foods eaten daily over a $3 \mathrm{~d}$ period twice during each intervention in addition to completing a daily checklist of the study food items. Training for completing food intake records was provided by study dietitians and food records were analysed with the participants when they visited the clinic. Daily energy and macronutrient intakes were calculated by using Diet 4 Nutritional Calculation software (Xyris Software, Highgate Hill, Qld, Australia) based on Australian food composition tables and compositional data on the test products.

Compliance with the study protocol was calculated by measuring differences in the amount of test foods issued and returned for each period and compatibility with that reported in the test food checklists. Refined cereal intake was $99 \mathrm{~g}$ with $96 \%$ compliance, wholemeal wheat intake was $97 \mathrm{~g}$ with $94 \%$ compliance and intake of Himalaya 292 was 96 g with $94 \%$ compliance.

\section{Sample processing and analyses}

Biochemical, nutrient and microbiological analyses were performed in duplicate using standard published procedures. Samples of each cereal test food were obtained during the second intervention period and freeze dried to constant weight, ground to pass through a $0.5 \mathrm{~mm}$ sieve using a cyclonic mill (Cyclotec 1093; Tecator, Höganäs, Sweden) and proximate and other analyses then performed on this material. Moisture was calculated as loss in mass resulting from lyophilisation. The gravimetric method of Prosky et $a l .{ }^{30}$ was used to determine TDF. Total, and soluble and insoluble neutral NSP (NNSP) were measured by the gas chromatographic procedure of Theander et $a l^{31}$ subject to a slight modification which involved a $2 \mathrm{~h}$ hydrolysis with $1 \mathrm{M}$-sulfuric acid followed by centrifugation for insoluble NNSP, and hydrolysis using 2 M-trifluoroacetic acid for soluble NNSP. Total starch was analysed according to the enzymic method of McCleary et al. ${ }^{32}$ using a commercial assay kit (K-TSTA; Megazyme International Ireland Ltd, Bray, Republic of Ireland). Fat content was determined gravimetrically after enzymic digestion of samples with clarase followed by homogenisation and extraction with chloroform-methanol ${ }^{33}$ as outlined by the Association of the Official Analytical Chemists (AOAC official method 983.23). Simple sugars were extracted with aqueous methanol $(80 \mathrm{ml} / 100 \mathrm{ml}$; AOAC method 982.14) and then quantified by HPLC using a polyamine-bonded polymeric gel column, acetonitrile-water $(75: 25, \mathrm{v} / \mathrm{v})$ as the mobile phase and a refractive index detector. Total $\mathrm{N}$ was analysed by the Dumas combustion method ${ }^{34}$ using an automated $\mathrm{N}$ analyser (model 1500; Carlo Erba, Milan, Italy). The protein content of food samples $(\mathrm{g} / 100 \mathrm{~g})$ was estimated by multiplying $\mathrm{N}$ by $6 \cdot 25$.

Urine samples were thawed at room temperature and samples assayed for creatinine by the Jaffe colorimetric method using a commercial kit (Metra $^{\mathrm{TM}}$ Creatinine Assay Kit no. 8009; Quidel Corp., San Diego, CA, USA). Phenols were determined by an HPLC procedure based on the methods of Murray \& Adams $^{35}$ and Yoshikawa et al. ${ }^{36}$. Briefly, samples containing internal standard (4-ethyl-phenol, $0.3 \mathrm{mmol} / \mathrm{l}$; Sigma Aldrich, Castle Hill, NSW, Australia) were acidified with $2 \mathrm{M}-\mathrm{HCl}$ and boiled for $30 \mathrm{~min}$ before distilling under vacuum. Distillates were analysed for phenol and p-cresol using a reverse-phase Chromopack HPLC Microsorb column $(250 \times 4.6 \mathrm{~mm}$; Varian, Melbourne, Victoria, Australia). The mobile phase was acetonitrile-water $(30: 70, \mathrm{v} / \mathrm{v})(\mathrm{pH} 3 \cdot 2)$, the flow rate was $1 \mathrm{ml} / \mathrm{min}$, and the injection volume was $20 \mu \mathrm{l}$. The column oven temperature was set at $28^{\circ} \mathrm{C}$. Phenol and $p$-cresol were detected at a wavelength of $275 \mathrm{~nm}$ with a UV/Vis-detector (LC1200; GBC, Adelaide, SA, Australia).

Stools from each volunteer were thawed at room temperature, pooled within collection period, mixed thoroughly, the composite weight recorded, and then duplicate samples analysed as follows. For determination of DM, samples weighing approximately $3 \mathrm{~g}$ were freeze dried to constant weight. For SCFA determination, samples $(1 \mathrm{~g})$ were diluted threefold with internal standard (1.68 mM-heptanoic acid; Sigma Aldrich), centrifuged $\left(3000 \mathrm{~g}\right.$ for $15 \mathrm{~min}$ at $4^{\circ} \mathrm{C}$ ) and the $\mathrm{pH}$ of the resultant supernatant fraction measured by inserting an appropriate glass probe. A sample $(150 \mu \mathrm{l})$ of supernatant fraction was then acidified with $30 \mu \mathrm{l} 0 \cdot 16 \mathrm{M}$ orthophosphoric acid and distilled under vacuum. Individual SCFA in the distillates were separated and quantified by capillary GC (5890 series II; Hewlett Packard, North Ryde, NSW, Australia) as described previously ${ }^{27}$. The GC was equipped with a flame ionisation detector, split-less injector and a Zebron ZB-FFAP $30 \mathrm{~m} \times 0.53 \mu \mathrm{m}$ capillary column with $0.1 \mu \mathrm{m}$ film thickness (Phenomenex, Lane Cove, NSW, Australia). Injector and detector temperatures were both $210^{\circ} \mathrm{C}$, and the column temperature program was $120^{\circ} \mathrm{C}$ held for $0.5 \mathrm{~min}$ and then raised at $30^{\circ} \mathrm{C} / \mathrm{min}$ to reach a final column temperature of $190^{\circ} \mathrm{C}$. The carrier gas used was $\mathrm{He}$ (head pressure $50 \mathrm{kPa}$ ) and an injection volume of $0.2 \mu$ l was used.

Total SCFA concentration was calculated as the sum of acetic, propionic, butyric, isobutyric, caproic, isovaleric and valeric acid concentrations. Faecal SCFA excretion ( $\mathrm{mmol} / 2 \mathrm{~d}$ ) was calculated as: SCFA concentration $(\mathrm{mmol} / \mathrm{l}) \times$ wet faecal weight $(\mathrm{g} / 2 \mathrm{~d}) \times$ faecal moisture content $(\mathrm{g} / 100 \mathrm{~g}) \times 10^{-5}$.

Ammonia in faeces was measured using the indophenol blue procedure ${ }^{37}$. Faecal specimens $(0.5 \mathrm{~g})$ were mixed with 9 volumes of distilled water and the slurry centrifuged at 
$2000 \mathrm{~g}$ for $10 \mathrm{~min}$. A sample $(100 \mu \mathrm{l})$ of supernatant fraction was diluted 1:10 with water and $2 \mathrm{ml}$ of an aqueous phenol $(0.1 \mathrm{~mol} / \mathrm{l})$ plus sodium nitroprusside $(0.17 \mathrm{mmol} / \mathrm{l})$ solution added followed immediately by $2 \mathrm{ml}$ of alkaline sodium hypochlorite $(5.4 \mathrm{mmol} / \mathrm{l})$. The samples were vortexed before being heated for $10 \mathrm{~min}$ at $60^{\circ} \mathrm{C}$ in a shaking water-bath and then quickly cooled to room temperature. The optical density $(625 \mathrm{~nm})$ of the blue-coloured endproduct (indophenol) that formed was measured by colorimetry. Ammonia concentration was determined from a standard curve based on appropriate reference solutions.

Faecal phenols were determined using the same reversephase HPLC procedure as outlined for urine samples. Each faecal sample was diluted 3-fold with 4-ethyl-phenol $(4.1 \mathrm{mmol} / \mathrm{l})$ as internal standard and the slurry centrifuged at $3000 \mathrm{~g}$ for $15 \mathrm{~min}$ at $4^{\circ} \mathrm{C}$. A $150 \mu \mathrm{l}$ sample of supernatant fraction was acidified with $30 \mu \mathrm{l} 0 \cdot 16 \mathrm{M}-o$-phosphoric acid and distilled under vacuum at low temperature. Phenol and $p$-cresol were isolated and separated by the same HPLC method referred to earlier except that an injection volume of $30 \mu l$ was used.

Bacteria were enumerated using conventional selective plating methods. Subsamples of homogenised faeces were mixed with $90 \mathrm{ml}$ of pre-reduced buffered peptone water (20 g/l buffered peptone (Oxoid CM509; Oxoid Australia Pty Ltd, West Heidelberg, Victoria, Australia), $0.5 \%$ cysteine $\mathrm{HCl}$ and $0 \cdot 1 \%$ Tween 80 ) and the resultant suspension thoroughly homogenised followed by 10 -fold serial dilutions. Samples $(100 \mu l)$ of appropriate dilutions were inoculated in duplicate directly onto plates containing either Bifidus blood ${ }^{38}$, Rogosa (Oxoid CM627), Columbia blood (Oxoid CM 331) or chromogenic Escherichia colicoliform (Oxoid CM956) medium for the selective enumeration of bifidobacteria, lactobacilli, total anaerobes, and E. coli, coliforms and total aerobes, respectively. Bifidus blood, Columbia Blood and Rogosa plates were incubated at $37^{\circ} \mathrm{C}$ under anaerobic conditions (Anaerogen Compact system; Oxoid AN010C) for between 3 and $7 \mathrm{~d}$ depending on the culture. Chromogenic plates were incubated at $37^{\circ} \mathrm{C}$ under aerobic conditions for $24 \mathrm{~h}$. Colonies characteristic of each bacterial group were visually counted and the concentration calculated as $\log _{10}$ colony-forming units/g wet weight.

\section{Calculations and statistical analysis}

Data were analysed using SAS software (release 8.02; SAS Institute Inc., Cary, NC, USA). Eighteen volunteers completed the study but one subject did not undertake complete faecal collection on two occasions. Data for this non-compliant individual, and for the three volunteers who failed to finish the study, were excluded from the final statistical analysis. The results are presented as mean values with their standard errors for seventeen observations, except where otherwise indicated.

Effects of the dietary treatments were determined by ANOVA with the following terms included in the model: subject, period, carryover and treatment. Carryover and period were subsequently removed from the model as they were not found to be significant $(P>0 \cdot 05)$. Fisher's least significant difference test was applied to assess pair-wise comparisons between individual treatments. Logarithmic transformation of bacteriological data was performed before statistical analysis and the results expressed as $\log _{10}$ colony-forming units/ $\mathrm{g}$ wet weight. Repeated-measures ANOVA was used to examine estimated nutrient intake data. A $P$ value $<0.05$ was considered statistically significant.

\section{Results}

Body weights of the volunteers remained steady throughout the study and were similar at the end of each of the three dietary interventions (refined cereal, $80.1 \mathrm{~kg}$; wholemeal wheat, $80.5 \mathrm{~kg}$; Himalaya $292,79.3 \mathrm{~kg} ; P>0.05$ ) and were not different from baseline. Mean intake of test cereals estimated from diet records was 96, 97 and $99 \mathrm{~g}$ for the Himalaya 292, wholemeal wheat and refined cereal diets, respectively, which also indicated good compliance. The study foods were well accepted and their consumption was not associated with any serious adverse effects. There were no significant differences in energy or macronutrient intake between the different dietary interventions (Table 2). TDF intake was different for each of the diets (all comparisons $P<0 \cdot 001$ ). Himalaya 292 and whole-wheat diets supplied about an extra 23 and $11 \mathrm{~g}$ dietary fibre/d, respectively, over the $21 \mathrm{~g} / \mathrm{d}$ (approximately) consumed during the low-fibre period.

Faecal output was greater when Himalaya 292 or the wholewheat diets were consumed than the refined cereal diet $(P<0.05$; Table 3$)$. Faecal bulking was about $8 \%$ larger for Himalaya 292 than wholemeal wheat but the difference was not statistically significant. Frequency of defecation was not different between treatments. Faeces were drier on the refined cereal diet than the wholemeal diets $(P=0 \cdot 04$, Himalaya 292 and wholemeal wheat data combined) but the effects of the individual high-fibre diets were not significant (Table 3). Faecal pH was lower with Himalaya 292 than either the wholemeal wheat or refined cereal diets $(P<0.05)$.

Table 3. Effect of dietary treatments on faecal weight, water content and $\mathrm{pH}$, and defecation frequency (Mean values with their standard errors for seventeen observations)

\begin{tabular}{|c|c|c|c|c|c|c|}
\hline & \multicolumn{2}{|c|}{ Refined cereal } & \multicolumn{2}{|c|}{ Wholemeal wheat } & \multicolumn{2}{|c|}{ Himalaya 292} \\
\hline & Mean & SE & Mean & SE & Mean & SE \\
\hline Wet weight $(g / 48 h)$ & $300^{\mathrm{a}}$ & 38 & $374^{\mathrm{b}}$ & 49 & $400^{b}$ & 44 \\
\hline Water $(\mathrm{g} / 100 \mathrm{~g})$ & $73 \cdot 8$ & $1 \cdot 7$ & $76 \cdot 8$ & 1.5 & $77 \cdot 3$ & $1 \cdot 2$ \\
\hline $\mathrm{pH}$ & $7 \cdot 24^{a}$ & 0.14 & $7 \cdot 24^{a}$ & $0 \cdot 17$ & $6 \cdot 98^{b}$ & 0.17 \\
\hline Defecation frequency (motions/48 h) & $2 \cdot 0$ & 0.2 & $2 \cdot 2$ & $0 \cdot 2$ & $2 \cdot 1$ & 0.2 \\
\hline
\end{tabular}

${ }^{\mathrm{a}, \mathrm{b}}$ Mean values within a row with unlike superscript letters are significantly different $(P<0.05)$. 
Faecal concentrations of total and major individual SCFA were similar for the refined cereal and wholemeal wheat treatments (Table 4). The faecal concentrations of acetate and propionate for these two diets were not significantly different from Himalaya 292. However, faecal butyrate was significantly higher on the Himalaya 292 diet than with the other two treatments, with concentrations 27 and $42 \%$ greater than wholemeal wheat and control (refined) diets, respectively. Faecal total SCFA, acetate and propionate excretion was similar for the two wholegrain cereals and significantly greater than when the control diet was consumed. However, the combination of higher concentrations and greater stool bulk in subjects consuming Himalaya 292 led to a $41-91 \%$ increase in faecal excretion of butyrate relative to the wholemeal wheat and refined cereal diets (Table 4).

The dietary interventions had no significant effect on faecal ammonia or phenol concentrations (data not shown). However, $p$-cresol concentrations were significantly lower with Himalaya 292 (426 (SE 71) nmol/g) and whole wheat (363 (SE 65) $\mathrm{nmol} / \mathrm{g}$ ) than with the control diet (641 (SE 115) $\mathrm{nmol} / \mathrm{g})(P<0 \cdot 05)$. Diet also had no effect on urine creatinine concentration, and phenol and $p$-cresol content relative to creatinine (data not shown). Urine $p$-cresol concentration was greater on the wholemeal wheat diet compared with refined wheat (7.4 (SE 1.6) and 4.2 (SE 0.6) $\mu \mathrm{g} / \mathrm{ml} ; P<0.05)$ whereas Himalaya $292(5.7$ (SE 0.9$) \mu \mathrm{g} / \mathrm{ml})$ was not significantly different from these treatments.

Neither the faecal numbers per $g$ of stool nor the daily excretion of aerobic, bifidobacteria, lactobacilli or coliform bacteria differed between treatments (data not shown). However, the excretion of anaerobes was significantly $(P<0.05)$ higher during the consumption of Himalaya 292 foods compared with the refined foods with mean values of 11.49 (SE 0.13 ) and 11.84 (SE 0.14) $\log _{10}$ colony-forming units/d, respectively. Excretion did not differ from the other treatments during the whole-wheat period with a mean value of 11.73 (SE 0.08) $\log _{10}$ colony-forming units/d.

\section{Discussion}

The aim of the present study was to compare the effects of foods made from the novel barley variety (Himalaya 292) and from wheat on indices of bowel health. Both sets of foods were made from whole grains while a further comparison was with refined wheat products. As expected from the analytical data, TDF intakes were significantly higher during the wholegrain arms of the trial with mean values of 45 and $32 \mathrm{~g} /$ person per d for the Himalaya 292 and whole-wheat foods, respectively, compared with $21 \mathrm{~g} /$ person per $\mathrm{d}$ for the refined cereal products at equivalent levels of foods consumption. Compared with the refined cereal foods, consumption of Himalaya 292 foods resulted in $33 \%$ higher faecal weight, a lowering of faecal $\mathrm{pH}$ and higher faecal concentration and excretion of butyrate.

In comparison with wholegrain wheat, foods made from Himalaya 292 contained approximately double the level of TDF and about 80-90\% more NSP. The difference between the TDF and NSP values in the Himalaya 292 foods can be ascribed to a contribution by RS. Previous experiments with rats have shown that Himalaya 292 consumption leads to raised large-bowel starch (i.e. RS) by $100-200 \%$ at equivalent levels of dietary fibre ${ }^{27}$. Studies with human volunteers support these findings with lower glycaemic index values for Himalaya 292 foods relative to a standard barley or wheat ${ }^{29,39}$. While RS and glycaemic index are not synonymous, the lower values for the latter are suggestive of slower small-intestinal starch digestion and absorption in humans.

The randomised cross-over design is a strong one and the dietary records (plus the food returns) show good compliance and similar intakes of macronutrients during all three periods. It has been reported that food consumption was higher in the short term following meals containing Himalaya 292 compared with whole wheat ${ }^{39}$. This did not occur in the present study and body weight showed no change in any experimental period. Rates of withdrawal from the study were low $(n 3)$ and those that did so withdrew in the first study phase due to personal reasons $(n 1)$, an inability to eat the required amount (n 1) or abdominal discomfort attributed to the study foods (n 1). The only significant difference was in the greater TDF intake with the barley ( $45 \mathrm{~g} /$ person per d) and wheat whole grain $(32 \mathrm{~g} /$ person per $\mathrm{d})$ foods over the refined wheat $(20 \mathrm{~g} /$ person per d). Even considering these high fibre intakes, there were only a few reports overall of gastrointestinal upsets (bloating, distension, flatulence, etc) and they were unrelated to dietary treatment. Fibre consumption during the refined wheat period was high by international standards but is consistent with earlier findings in another nutritional study with Australians ${ }^{40}$, in population surveys of Australians ${ }^{22}$ and a large study of older Australians ${ }^{41}$. Intakes of this

Table 4. Effect of dietary treatments on faecal excretion of short-chain fatty acids expressed as concentration (mmol/l) and amount (mmol/48 $\mathrm{h}$ ) (Mean values with their standard errors for seventeen observations)

\begin{tabular}{|c|c|c|c|c|c|c|c|c|c|c|c|c|}
\hline & \multicolumn{6}{|c|}{ Concentration (mmol/l) } & \multicolumn{6}{|c|}{ Amount (mmol/48 h) } \\
\hline & \multicolumn{2}{|c|}{ Refined cereal } & \multicolumn{2}{|c|}{$\begin{array}{c}\text { Wholemeal } \\
\text { wheat }\end{array}$} & \multicolumn{2}{|c|}{ Himalaya 292} & \multicolumn{2}{|c|}{ Refined cereal } & \multicolumn{2}{|c|}{$\begin{array}{c}\text { Wholemeal } \\
\text { wheat }\end{array}$} & \multicolumn{2}{|c|}{ Himalaya 292} \\
\hline & Mean & $\mathrm{SE}$ & Mean & SE & Mean & $\mathrm{SE}$ & Mean & SE & Mean & SE & Mean & SE \\
\hline Total SCFA* & $111 \cdot 6$ & $10 \cdot 9$ & $111 \cdot 1$ & $10 \cdot 6$ & $133 \cdot 0$ & $11 \cdot 6$ & $28 \cdot 8^{\mathrm{a}}$ & $5 \cdot 9$ & $34 \cdot 6^{\mathrm{a}, \mathrm{b}}$ & $6 \cdot 4$ & $45 \cdot 2^{b}$ & $7 \cdot 2$ \\
\hline Acetate & 69.4 & $7 \cdot 4$ & $67 \cdot 7$ & $7 \cdot 0$ & 79.5 & $7 \cdot 0$ & $18 \cdot 4^{\mathrm{a}}$ & $4 \cdot 2$ & $21 \cdot 3^{a, b}$ & 4.0 & $27 \cdot 3^{b}$ & 4.6 \\
\hline Butyrate & $20 \cdot 9^{a}$ & $3 \cdot 1$ & $23 \cdot 4^{a}$ & 3.0 & $29 \cdot 7^{b}$ & 3.5 & $5 \cdot 6^{a}$ & $1 \cdot 3$ & $7 \cdot 6^{a}$ & 1.7 & $10 \cdot 7^{b}$ & $2 \cdot 1$ \\
\hline
\end{tabular}

${ }^{\mathrm{a}, \mathrm{b}}$ Mean values within a row for concentration or amount with unlike superscript letters are significantly different $(P<0.05)$

* Sum of acetic, propionic, butyric, isobutyric, caproic, isovaleric and valeric acids. 
order have been reported to promote laxation in young ${ }^{42}$ and elderly ${ }^{43}$ subjects but higher intakes do not appear to increase defecation frequency ${ }^{42}$. The present data replicate the latter finding. The high stool weights $(300 \mathrm{~g} / 48 \mathrm{~h})$ recorded during the refined wheat period are consistent with dietary fibre intake. They are of the order which has been suggested as a minimum value for protection against colon cancer ${ }^{44}$ and are associated with improvements in a variety of putative markers of bowel health ${ }^{45}$. Both high-wholegrain periods showed increased stool output. Faecal bulking is in proportion to dietary fibre intake with wheat bran as a possible standard in this regard ${ }^{46}$ with an increase of about $5 \mathrm{~g}$ stool/g fibre (as NSP) consumed ${ }^{47}$. The increment of $5.1 \mathrm{~g} \mathrm{stool} / \mathrm{g}$ fibre (measured as NSP) with the whole-wheat diet compared with $2.9 \mathrm{~g}$ stool/g NSP for barley foods accords with this suggestion. The increase in stool weight in response to the barley products is similar to that reported for oats and maize, about $3.4 \mathrm{~g}$ faeces for each additional $g$ dietary fibre. The difference between the two dietary treatments may reflect the fermentabilities of the major fibre components of whole wheat and the new barley. The latter is higher in soluble fibres which, in general, seem to be relatively more fermentable than insoluble fibres, making them less effective faecal-bulking agents ${ }^{47}$. In the present study, $76 \%$ of the total NSP in the whole-wheat foods was insoluble compared with $29 \%$ in the barley foods. Nevertheless, stool mass was $20 \%$ higher than anticipated when the Himalaya 292 foods were consumed $(100 \mathrm{~g} / 48 \mathrm{~h}$ compared with an estimated $80 \mathrm{~g} /$ $48 \mathrm{~h}$ ). These data support the suggestion that other dietary, non-NSP, components (for example, RS) can contribute to faecal bulking ${ }^{45}$. It is possible also that differences in the water-holding capacity of the unfermented residues may also play a role ${ }^{48}$. However, faecal water content did not differ between treatments, suggesting that this was not a contributor. Finally, it is possible that some of the difference was due to greater bacterial excretion, although we have no measure of the total biomass.

As noted, previous animal studies have shown more largebowel starch, greater digesta mass and higher SCFA at equivalent fibre intakes for Himalaya 292 than comparable grains. The present study extends these findings with greater SCFA excretion and lower faecal $\mathrm{pH}$ following consumption of foods containing Himalaya 292 27,28 . The present experiment was conducted with equivalent servings of foods (rather than matched intakes of dietary fibre), as this conforms to human consumption patterns. It should be noted also that we used consumer foods prepared by industrial processes involving heat. We acknowledge also that it is not possible to specify that the effects were due to RS alone. Based on the animal studies with Himalaya 292, it was expected that faecal SCFA would be higher during both the whole-wheat and (particularly) the barley periods. However, the impact of whole wheat on SCFA concentrations and excretion was not significant relative to the refined wheat foods. Only Himalaya 292 foods raised the excretion of butyrate significantly. This could be a reflection of the difference in faecal bulk. Greater stool mass is associated with more rapid transit ${ }^{49,50}$ which is a determinant of faecal SCFA through diminished colonic absorption $^{13}$. However, transit alone may not account for the higher faecal butyrate levels during the Himalaya 292 period. Evidence for greater large-bowel fermentation during consumption of barley foods came from the faecal $\mathrm{pH}$ values which were significantly lower than in the other two periods. Similar data were obtained in rats and pigs ${ }^{27,28}$. Lowering of $\mathrm{pH}$ comes through direct acidification by increased SCFA concentrations and, also, through the fixing of $\mathrm{NH}_{4}{ }^{+}$, as greater bacterial mass ${ }^{51}$. As there were no differences in faecal ammonia, it appears that the higher SCFA (through greater fermentation) were responsible. Lowered $\mathrm{pH}$ is thought to promote bowel health through altering the absorption of potentially toxic metabolites and preventing overgrowth by potential pathogenic bacteria ${ }^{13}$.

Greater polysaccharide fermentation can lower the levels of bacterial protein degradation products such as phenols and cresols $^{52}$. These compounds have been linked to a greater risk of cancers, including those of the large bowel ${ }^{23}$. $p$-Cresol (but not phenols) was lowered in both faeces and urine during both wholegrain periods, indicating lower exposure to these agents.

Previous studies have shown that RS can function as a prebiotic, stimulating the growth of lactic acid bacteria in the bowel $^{53}$. In the present study no differences were observed in faecal bifidobacteria and lactobacilli numbers. This is consistent with our finding of a lack of prebiotic action of Himalaya 292 in pigs although numbers of anaerobes and aerobes were increased ${ }^{28}$. These data provide further evidence that not all RS stimulate proliferation of probiotic bacteria ${ }^{53}$. However, it must be recognised that the culture-based techniques that were used to enumerate faecal bacteria in our studies on the novel barley may not have had the necessary sensitivity to detect subtle changes in bacterial populations. The observation that faecal anaerobes were more numerous when volunteers were on the barley diet is consistent with greater supply of fermentable substrate.

Prototype foods made from the new barley were a rich source of fibre and their texture was acceptable to volunteers who had no apparent difficulty adapting to the wholegrain dietary regimen. The use of Himalaya 292 offers an opportunity to expand and diversify the range of food products available to consumers, thereby making it easier for them both to increase their intake of fibre and to meet dietary recommendations for increased consumption of whole grains.

\section{Acknowledgements}

The present study was supported financially by CSIRO and ACVL Ltd. The authors thank Michael Mular and Sylvia Usher for compositional analysis of food ingredients, Debbie Davies and Corinna Flory for sample processing and biochemical and bacterial analyses, and Anne McGuffin, Kathryn Bastiaans and Julia Weaver for recruitment and management of volunteers. Russell Heywood and Zhongyi Li at CSIRO Plant Industry managed the growth, harvesting and milling of grain samples and staff at Food Science Australia (North Ryde, NSW, Australia) stabilised the grains with heat. Ken Quail and staff at BRI Ltd (North Ryde, NSW, Australia) are acknowledged for developing and manufacturing the cereal-based foods used in the human study.

M. K. M. and D. L. T. are named inventors of a disclosure describing the barley cultivar (PCT/WO02/37 955/A1 Barley plant with high amylose starch). They have no financial interest in this invention, which was made as part of their normal duties as employees of CSIRO. 


\section{References}

1. Flight I \& Clifton P (2006) Cereal grains and legumes in the prevention of coronary heart disease and stroke: a review of the literature. Eur J Clin Nutr 60, 1145-1159.

2. National Health and Medical Research Council (2003) Dietary Guidelines for Australian Adults. Endorsed 10 April 2003. Canberra: Commonwealth of Australia.

3. Dietary Guidelines Advisory Committee (2004) Report of the Dietary Guidelines Advisory Committee on the Dietary Guidelines for Americans, 2005. Washington, DC: US Department of Health and Human Services.

4. La Vecchia C, Chatenoud L, Negri \& Franceschi S (2003) Whole cereal grains, fibre and human cancer - wholegrain cereals and cancer in Italy. Proc Nutr Soc 62, 45-49.

5. Murtaugh MA, Jacobs DR Jr, Jacob B, Steffen LM \& Marquart L (2003) Epidemiological support for the protection of whole grains against diabetes. Proc Nutr Soc 62, 143-149.

6. Truswell AS (2002) Cereal grains and coronary heart disease. Eur J Clin Nutr 56, 1-14.

7. Koh-Banerjee P, Franz M, Sampson L, Liu S, Jacobs DR Jr, Spiegelman D, Willett W \& Rimm E (2004) Changes in whole-grain, bran, and cereal fibre consumption in relation to 8-y weight gain among men. Am J Clin Nutr 80, 1237-1245.

8. Marlett JA, McBurney MI \& Slavin JL (2002) Position of the American Dietetic Association: health implications of dietary fibre. J Am Diet Assoc 102, 993-1000.

9. Aldoori WH, Giovannucci EL, Rockett HR, Sampson L, Rimm EB \& Willett WC (1998) A prospective study of dietary fibre types and symptomatic diverticular disease in men. $J$ Nutr 128, 714-719.

10. Bingham SA, Day NE, Luben R, et al. (2003) Dietary fibre in food and protection against colorectal cancer in the European Prospective Investigation into Cancer and Nutrition (EPIC): an observational study. Lancet 361, 1496-1501.

11. Cummings JH \& Macfarlane GT (1991) The control and consequences of bacterial fermentation in the human colon. $J$ Appl Bacteriol 70, 443-459.

12. Brouns F, Kettlitz E \& Arrigoni E (2002) Resistant starch and the butyrate revolution. Trends Food Sci Technol 13, 251-261.

13. Topping DL \& Clifton PM (2001) Short-chain fatty acids and human colonic function: roles of resistant starch and nonstarch polysaccharides. Physiol Rev 81, 1031-1064.

14. Burkitt DP (1973) Some diseases characteristic of modern Western civilization. BMJ 1, 274-278.

15. Segal I (2002) Physiological small bowel malabsorption of carbohydrates protects against large bowel diseases in Africans. J Gastroenterol Hepatol 17, 249-252.

16. Weaver GA, Krause JA, Miller TL \& Wolin MJ (1992) Cornstarch fermentation by the colonic microbial community yields more butyrate than does cabbage fibre fermentation; cornstarch fermentation rates correlate negatively with methanogenesis. Am J Clin Nutr 55, 70-77.

17. Cassidy A, Bingham SA \& Cummings JH (1994) Starch intake and colorectal cancer risk: an international comparison. $\mathrm{Br} J$ Cancer 69, 937-942.

18. van Munster IP, Tangerman A \& Nagengast FM (1994) Effect of resistant starch on colonic fermentation, bile acid metabolism and mucosal proliferation. Dig Dis Sci 39, 831-842.

19. Caderni G, Luceri C, Lancioni L, Tessitore L \& Dolara P (1998) Slow-release pellets of sodium butyrate increase apoptosis in the colon of rats treated with azoxymethane, without affecting aberrant crypt foci and colonic proliferation. Nutr Cancer 30, $175-181$.

20. Toden S, Bird AR, Topping DL \& Conlon MA (2007) Dosedependent reduction of dietary protein-induced colonocyte DNA damage by resistant starch in rats correlates more highly with caecal butyrate than with other short chain fatty acids. Cancer Biol Ther 6, 253-258.

21. Muir JG, Yeow EGW, Keogh J, Pizzey C, Bird AR, Sharpe K, O'Dea K \& Macrae F (2004) Combining wheat bran with resistant starch has more beneficial effects on fecal indices than does wheat bran alone. Am J Clin Nutr 79, 1020-1028.

22. Baghurst PA, Baghurst KI \& Record SJ (1996) Dietary fibre, non-starch polysaccharides and resistant starch - a review. Food Aust 48, S3-S35.

23. Bingham S (2000) Diet and colorectal cancer prevention. Biochem Soc Trans 28, 12-16.

24. Brown I, McNaught K \& Moloney E (1995) Hi-maize ${ }^{\mathrm{TM}}$ - new directions in starch technology and nutrition. Food Aust 47, 272-275.

25. Colonna P \& Mercier C (1985) Gelatinization and melting of maize starches with normal and high amylose phenotypes. Phytochemistry 24, 1667-1674.

26. Morell MK, Kosar-Hashemi B, Cmiel M, Samuel MS, Chandler P, Rahman S, Buleon A, Batey IL \& Li ZY (2003) Barley sex6 mutants lack starch synthase IIa activity and contain a starch with novel properties. Plant $J$ 34, 173-185.

27. Bird AR, Flory C, Davies DA, Usher S \& Topping DL (2004) A novel barley cultivar (Himalaya 292) with a specific gene mutation in starch synthase IIa raises large bowel starch and short-chain fatty acids in rats. J Nutr 134, 831-835.

28. Bird AR, Jackson M, King RA, Davies DA, Usher S \& Topping DL (2004) A novel high-amylose barley cultivar (Hordeum vulgare var Himalaya 292) lowers plasma cholesterol and alters indices of large-bowel fermentation in pigs. Br J Nutr 92, 607-615.

29. Topping DL, Morell MK, King RA, Li ZY, Bird AR \& Noakes M (2003) Resistant starch and health - Himalaya 292, a novel barley cultivar to deliver benefits to consumers. Starch-Stärke 55, 539-545.

30. Prosky L, Asp NG, Furda I, DeVries JW, Schweizer TF \& Harland BF (1985) Determination of total dietary fibre in foods and food products: collaborative study. $J$ Assoc Off Anal Chem 68, 677-679.

31. Theander O, Aman P, Westerlund E, Andersson R \& Pettersson D (1995) Total dietary fibre determined as neutral sugar residues, uronic acid residues, and Klason lignin (the Uppsala method): collaborative study. J AOAC Int 78, 1030-1044.

32. McCleary B, Solah V \& Gibson T (1994) Quantitative measurement of total starch in cereal flours and products. J Cereal Sci 20, $51-58$.

33. Daugherty C \& Lento H (1983) Chloroform-methanol extraction method for determination of fat in foods. J Assoc Off Anal Chem 66, $927-932$.

34. Kirsten W, Ternud I \& Hesselius G (1984) Automatic simultaneous determination of nitrogen and moisture in grain with or without weighing. J Agric Food Chem 32, 279-284.

35. Murray KE \& Adams RF (1988) Determination of simple phenols in faeces and urine by high-performance liquid chromatography. J Chromatogr 431, 143-149.

36. Yoshikawa M, Taguchi Y, Arashidani K \& Kodama Y (1986) Determination of cresols in urine by high-performance liquid chromatography. J Chromatogr 362, 425-429.

37. Chaney A \& Marvach E (1962) Modified reagents for determination of urea and ammonia. Clin Chem 8, 130-132.

38. Pachenari A, Conway P \& Playne M (2001) Bifidus-blood agar - a differentiating medium for the isolation and enumeration of bifidobacteria from faecal samples. Biosci Microflora 20, $85-88$.

39. Keogh JB, Lau CW, Noakes M, Bowen J \& Clifton PM (2007) Effects of meals with high soluble fibre, high amylose barley variant on glucose, insulin, satiety and thermic effect of food in healthy lean women. Eur J Clin Nutr 61, 597-604. 
40. McIntosh GH, Noakes M, Royle PJ \& Foster PR (2003) Wholegrain rye and wheat foods and markers of bowel health in overweight middle-aged men. Am J Clin Nutr 77, 967-974.

41. Barclay AW, Brand-Miller JC \& Mitchell P (2006) Macronutrient intake, glycaemic index and glycaemic load of older Australian subjects with and without diabetes: baseline data from the Blue Mountains Eye study. Br J Nutr 96, $117-123$.

42. Haack VS, Chesters JG, Vollendorf NW, Story JA \& Marlett JA (1992) Increasing amounts of dietary fibre provided by foods normalizes physiologic response of the large bowel without altering calcium balance or faecal steroid excretion. Am J Clin Nutr 68, 615-622.

43. Baghurst KI, Hope AK \& Down EC (1985) Dietary intake in a group of institutionalised elderly and the effect of a fibre supplementation programme on nutrient intake and weight gain. Community Health Stud 9, 99-108.

44. Cummings JH, Bingham SA, Heaton KW \& Eastwood MA (1992) Faecal weight, colon cancer risk, and dietary-intake of nonstarch polysaccharides (dietary fibre). Gastroenterology 103, 1783-1789.

45. Birkett AM, Jones GP, de Silva AM, Young GP \& Muir JG (1997) Dietary intake and faecal excretion of carbohydrate by Australians: importance of achieving stool weights greater than $150 \mathrm{~g}$ to improve faecal markers relevant to colon cancer risk. Eur J Clin Nutr 51, 625-632.
46. Topping DL (1998) Physiological effects of dietary carbohydrates in the large bowel: is there a need to recognise dietary fibre equivalents? Asia Pacific J Clin Nutr 8, Suppl., S22-S26.

47. Cummings JH (1993) The effect of dietary fibre on faecal weight and composition. In CRC Handbook of Dietary Fiber in Human Nutrition, 2nd ed., pp. 263-349 [GA Spiller, editor]. Boca Raton, FL: CRC Press.

48. McBurney MI (1991) Potential water-holding capacity and short-chain fatty acid production from purified fiber sources in a fecal incubation system. Nutrition 7, 421-424.

49. Burkitt DP, Walker AR \& Painter NS (1972) Effect of dietary fibre on stools and the transit-times, and its role in the causation of disease. Lancet ii, 1408-1412.

50. Read NW, Miles CA, Fisher D, Holgate AM, Kime ND, Mitchell MA, Reeve AM, Roche TB \& Walker M (1980) Transit of a meal through the stomach, small intestine, and colon in normal subjects and its role in the pathogenesis of diarrhea. Gastroenterology 79, 1276-1282.

51. Weber FL Jr (1997) Effects of lactulose on nitrogen metabolism. Scand J Gastroenterol 222, Suppl., 83-87.

52. Birkett A, Muir J, Phillips J, Jones G \& O’Dea K (1996) Resistant starch lowers faecal concentrations of ammonia and phenols in humans. Am J Clin Nutr 63, 766-772.

53. Topping DL, Fukushima M \& Bird AR (2003) Resistant starch as a prebiotic and synbiotic: state of the art. Proc Nutr Soc 62, $171-176$. 